\title{
Gram-scale production of a basidiomycetous laccase in Aspergillus niger
}

\author{
Yasmina Mekmouche, ${ }^{1, *}$ Simeng Zhou, ${ }^{1,2}$ Angela M. Cusano, ${ }^{1,}$ Eric Record, ${ }^{2}$ Anne Lomascolo, ${ }^{2}$ \\ Viviane Robert, ${ }^{1}$ A. Jalila Simaan, ${ }^{1}$ Pierre Rousselot-Pailley, ${ }^{1}$ Sana Ullah, ${ }^{1}$ Florence Chaspoul, ${ }^{3}$ and \\ Thierry Tron ${ }^{1}$
} Aix Marseille Université, CNRS, iSm2 UMR 7313, 13397 Marseille, France, ${ }^{1}$ Aix-Marseille Université, INRA, UMR 1163, Biotechnologie des Champignons Filamenteux, Faculté des
Sciences de Luminy-Polytech, Case 925, 13009 Marseille, France, ${ }^{2}$ and Aix-Marseille Université, CNRS, IMBE, UMR 7263, Laboratoire Chimie Physique et Prévention des Risques et Nuisances Technologiques, FR3098 ECCOREV, Faculté de Pharmacie, F-13005 Marseille, France ${ }^{3}$

\begin{abstract}
We report on the expression in Aspergillus niger of a laccase gene we used to produce variants in Saccharomyces cerevisiae. Grams of recombinant enzyme can be easily obtained. This highlights the potential of combining this generic laccase sequence to the yeast and fungal expression systems for large-scale productions of variants.
\end{abstract}

[Key words: Multicopper enzyme; Bioreactor; Aspergillus niger; Saccharomyces cerevisiae; Glycosylation]

Achievements in biocatalyzed reactions require robust methods of production for enzymes coming from natural biodiversity and/or for evolved enzymes. The multicopper oxidase laccase ( $p$-diphenol: $\mathrm{O}_{2}$ oxidoreductase, EC 1.10.3.2) is a popular biocatalyst for potential technological and bioremediation processes in addition to its use in organic synthesis (1). So far, laccases from plant, bacteria, ascomycetous and basidiomycetous fungi have been expressed in bacteria, yeasts, filamentous ascomycetes, basidiomycetes or plant with various success reaching occasionally expression levels close to a gram per litter in complex cellular contexts $(2,3)$. Improvement in the production of single laccase variants in a given host may be obtained through variations of cultivation conditions, induction or mutagenesis (mainly through directed evolution) (4,5). For practical reasons, prior to any rationalization, it may appear crucial first to select a generic laccase encoding sequence that is generously expressed in heterologous expression hosts. Having previously used the yeast Saccharomyces cerevisiae to produce LAC3 $\left(\mathrm{LAC}^{\mathrm{Sc}}\right)$ and several variants with yields in the $\mathrm{mg} / \mathrm{L}$ range $(6-8)$, we report here on the production of grams of LAC3 (LAC $3^{A n}$ ) in the industrially relevant generally recognized as safe (GRAS) ascomycete Aspergillus niger.

We successfully integrated the lac 3 cDNA to the genome of $A$. niger [strain D15\#26 $\left(\right.$ pyrg $\left.^{-}\right)$(prtT) (phmA) (9)] and selected the LAC3 highest producing transformants for their ability to oxidize ABTS (volumetric activity). We followed a construction strategy and selection procedures identical to those previously published (10). Prior to any adjustments, the laccase titter obtained in flask culture was multiplied by 10 comparing $S$. cerevisiae to $A$. niger recombinants

\footnotetext{
* Corresponding author. Tel.: +33 491289151; fax: +33 491288440.

E-mail address: y.mekmouche@univ-amu.fr (Y. Mekmouche).

$\S$ Present address: Center for Advanced Biomaterials for Health Care@CRIB, Istituto Italiano di Tecnologia, Largo Barsanti e Matteuccin, 5380125 Napoli, Italy.
}

(data not shown). In A. niger it is known that both the $\mathrm{pH}$ regulation and the type of agitation of automated bioreactor systems have a marked influence on heterologous expression. So, scouting for fermentation parameters was conducted on $0.5 \mathrm{~L}$ cultures with a BIOSTAT-Qbioreactor. Initial fermentation conditions ( $20 \mathrm{~g} / \mathrm{L}$ glucose, $\mathrm{pH} 5.5$, aeration of $0.6 \mathrm{VVM}$ (volume of air/volume of culture medium/min), $2 \times 10^{6} \mathrm{spore} / \mathrm{mL}$ inoculum) allowed us to reach a maximum of $6000 \mathrm{U} / \mathrm{L}(\sim 120 \mathrm{mg} / \mathrm{L}$, using syringaldazine as substrate) laccase in 7 days before the enzyme started to degrade. From this initial fermentation we varied individually four cultivation parameters susceptible to influence the laccase production and established step-by-step the conditions for a routine fermentation (Fig. S1). Briefly, varying the glucose concentration from $20 \mathrm{~g} / \mathrm{L}$ to $50 \mathrm{~g} / \mathrm{L}$ laccase activity increased from $18,000 \mathrm{U} / \mathrm{L}$ to $24,000 \mathrm{U} / \mathrm{L}$; doubling, then tripling the aeration rate laccase activity increase substantially from $18,000 \mathrm{U} / \mathrm{L}$ to $42,000 \mathrm{U} / \mathrm{L}$; on the other hand, either lowering the temperature from $28^{\circ} \mathrm{C}$ to $26^{\circ} \mathrm{C}$ or reducing the inoculum size by 2 orders of magnitude led to a significant decrease of laccase activity. Adjusting these four parameters resulted in a substantial increase in LAC3 titter to a $42,000 \mathrm{U} / \mathrm{L}$ corresponding to $840 \mathrm{mg} / \mathrm{L}$ of recombinant enzyme produced in a $0.5 \mathrm{~L}$ fermentor. In the subsequent up-scaled fermentation (Fig. 1A), owing to the fact that LAC3 is the major secretion product (Fig. 1B), a simple concentration and one chromatographic purification step (anionic exchanger, $50 \%$ final yield) allowed us to recover $2.3 \mathrm{~g}$ of LAC3 with a specific activity of $50 \mathrm{U} / \mathrm{mg}$ and a satisfactory level of homogeneity as controlled by UV/VIS spectroscopy $\left(A_{280} / A_{610}=15\right)$ and denaturing gel electrophoresis (SDS-PAGE, Fig. 2A).

All together, this represents a substantial 200-fold increase in laccase production as compared to our previous heterologous production in S. cerevisiae $(6,8)$. The yield reported here is comparable to that reported for an ascomycetous laccase produced in 
Version définitive du manuscrit publiée dans / Final version of the manuscript published in :

Journal of Bioscience and Bioengineering (2013), p. 1-3, DOI: 10.1016/j.jbiosc.2013.06.013

Journal homepage: http://www.elsevier.com/locate/jbiosc

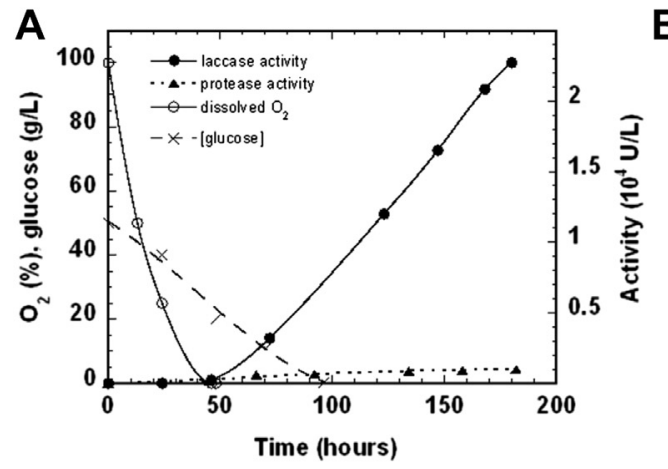

B

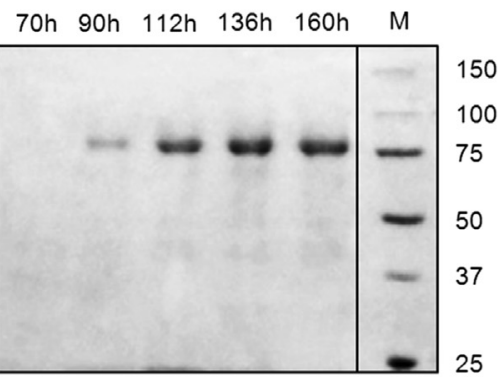

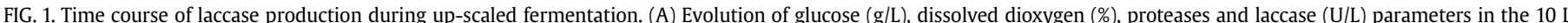

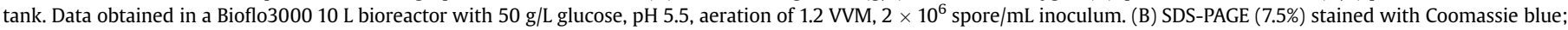

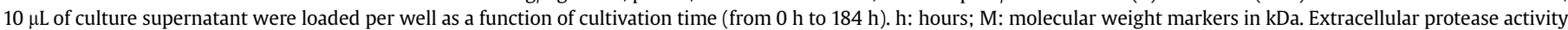

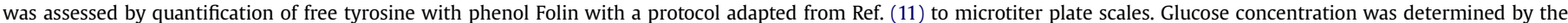
phenol sulphuric acid method (12).

the ascomycete Trichoderma reesei (2) and is routinely 3-4 times higher than that reported for basidiomycetous enzymes $(13,14)$ expressed in the ascomycete Aspergillus oryzae. It is also noteworthy that, strictly using here the same A. niger strain, the same vectors and the same basic medium, our laccase production is 10 times higher than that previously achieved expressing a Pycnoporus cinnabarinus gene (14). Beyond differences in fermentation strategies, this last case highlights the influence on the final yield of the nature of the primary sequence to express. This is of particular importance for the production of variants where the choice of the primary sequence to evolve might be determinant to the final yield of expensive enzymes.
The native LAC3 has never been purified from the fungus Trametes $\mathrm{sp}$. $\mathrm{C} 30$ but produced as a recombinant enzyme in S. cerevisiae (7) to which the form purified in A. niger was compared. The electrophoretic mobility of LAC $3^{A n}$ is substantially different from that of the same enzyme previously produced in $S$. cerevisiae as judged on gels ran either under denaturing or native conditions (Fig. 2A and B). Fungal laccases being glycoproteins, the discrepancy between the apparent molecular weight of $\mathrm{LAC}^{A n}(84 \mathrm{kDa})$ and that of $\mathrm{LAC}^{\mathrm{Sc}}$ (95 $\mathrm{kDa})$ is linked to the specificity of the glycosylation machineries of the respective hosts as supported by a shift towards the same apparent molecular weight ( $\approx 60 \mathrm{kDa}$ ) observed after an extended treatment of the two forms with an endoglycosidase (Fig. 2C and D).
A

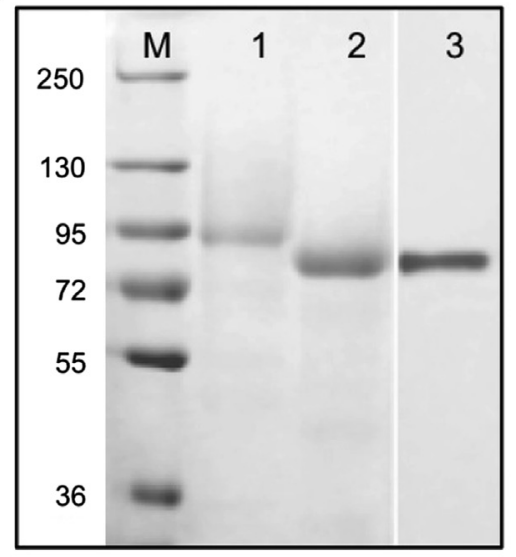

C

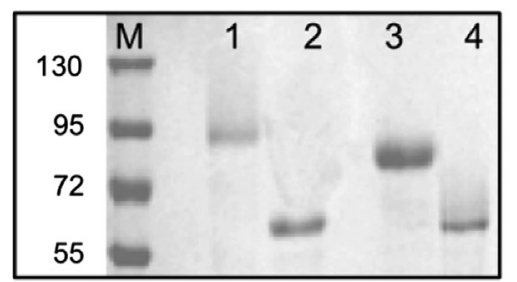

B

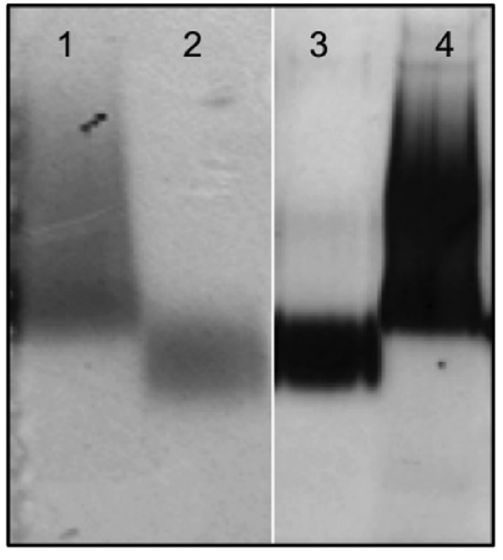

D

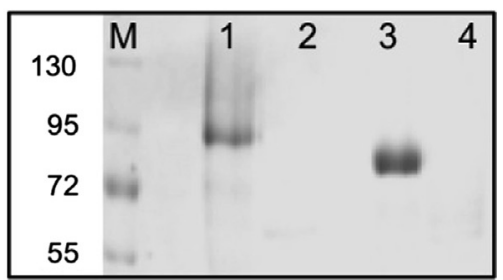

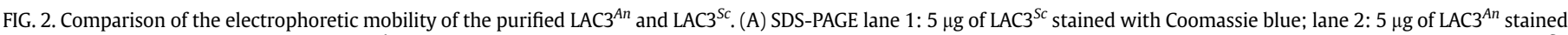

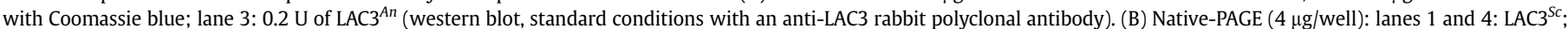

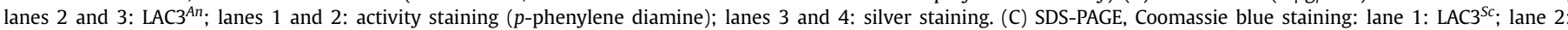

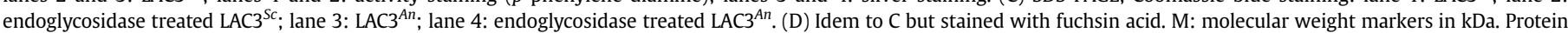

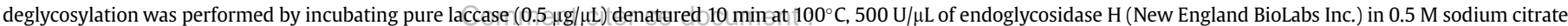
pH 5.5 for 45 hat 379 C.Y. (Auteur de correspondance), Zhou, S., Cusano, A. M., Record, E., Lomascolo, A. 
Version définitive du manuscrit publiée dans / Final version of the manuscript published in :

Journal of Bioscience and Bioengineering (2013), p. 1-3, DOI: 10.1016/j.jbiosc.2013.06.013

Journal homepage: http://www.elsevier.com/locate/jbiosc

TABLE 1. Apparent kinetic parameters for $\mathrm{LAC} 3^{A n}$ and $\mathrm{LAC} 3^{S C}$ in acetate buffer $(100 \mathrm{mM}, \mathrm{pH} 5.7)$ at $30^{\circ} \mathrm{C}$.

\begin{tabular}{|c|c|c|c|c|c|c|}
\hline \multirow[t]{2}{*}{ Apparent kinetic parameters ${ }^{a}$} & \multicolumn{2}{|c|}{$\operatorname{ABTS}\left(\varepsilon_{420 \mathrm{~nm}}=36000 \mathrm{M}^{-1} \mathrm{~cm}^{-1}\right)$} & \multicolumn{2}{|c|}{ Syringaldazine $\left(\varepsilon_{525 \mathrm{~nm}}=65000 \mathrm{M}^{-1} \mathrm{~cm}^{-1}\right)$} & \multicolumn{2}{|c|}{ Guaiacol $\left(\varepsilon_{465 \mathrm{~nm}}=12100 \mathrm{M}^{-1} \mathrm{~cm}^{-1}\right)$} \\
\hline & $\mathrm{LAC}^{A n}$ & $\mathrm{LAC}^{\mathrm{Sc}}$ & $\mathrm{LAC}^{A n}$ & $\mathrm{LAC}^{S C}$ & $\mathrm{LAC}^{A n}$ & $\mathrm{LAC}^{\mathrm{Sc}}$ \\
\hline$k_{\text {cat }}\left(\min ^{-1}\right)$ & $8378 \pm 126$ & $13955 \pm 300$ & $4756 \pm 157$ & $11038 \pm 271$ & $3087 \pm 79$ & $5278 \pm 511$ \\
\hline$K_{\mathrm{M}}(\mu \mathrm{M})$ & $734 \pm 54$ & $875 \pm 87$ & $16.2 \pm 1.5$ & $22.1 \pm 1.2$ & $4743 \pm 375$ & $4457 \pm 272$ \\
\hline$k_{\text {cat }} / K_{\mathrm{M}}\left(\min ^{-1} \mu \mathrm{M}^{-1}\right)$ & 11.4 & 16.0 & 282.4 & 499.5 & 0.65 & 1.2 \\
\hline
\end{tabular}

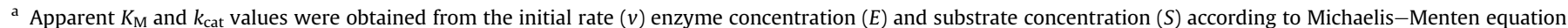

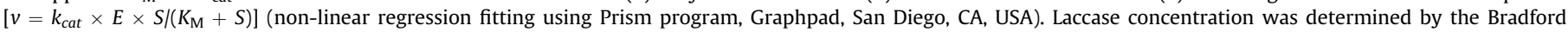
colorimetric assay using a lyophilized sample of pure laccase as the standard $(1-50 \mu \mathrm{g} / \mathrm{mL})(15)$.

Likewise, host specificities in post-translational processes probably account for the differences in catalytic efficiency observed for the enzyme purified from the two hosts (i.e., LAC3 ${ }^{A n}$ is globally $55-70 \%$ less efficient than $\mathrm{LAC}^{S C}$, see Table 1 ).

LAC ${ }^{A n} \mathrm{pH}$ tolerance (Fig. S2), copper ions content (4 atoms of copper), spectroscopic signatures and overall structure are features markedly close or even indistinguishable to those of $\mathrm{LAC}^{\mathrm{SC}}$ (Table S1). The general understanding on glycosylation fit a general non-specific effect on protein properties such as stabilization of conformation, protection against proteases and secretion of proteins (16). Accordingly, effect of glycans is likely related to local variations in the structure of the protein rather than to a global change in the enzyme structure (17). Therefore, despite the specificity of their respective glycosylation machineries, the $S$. cerevisiae and the $A$. niger expression systems can be profitably used in combination for protein engineering as shown recently with the expression of an evolved laccase mutant in A. niger (18). Moreover, the amount of laccase produced in $A$. niger opens the way for a valorization of laccases properties in the construction of artificial metalloenzymes $(7,19,20)$.

In conclusion, we have described the heterologous expression of a basidiomycetous laccase gene in a GRAS organism which secretes the recombinant enzyme at a level close to the g/L. Simple adjustments of fermentation operations in a bioreactor allow the production of grams of the recombinant laccase. As the recombinant enzyme is the main secretion product of the host its subsequent purification is largely facilitated. This enzyme is representative of the laccase family. The form produced in A. niger is functionally similar to the one previously produced in $S$. cerevisiae. Perfectly amenable to synthetic evolution, secreted at substantial levels in industrially relevant organisms, this multicopper oxidase is a potential generic for the development of low cost means of production of tailored biocatalysts.

Supplementary data related to this article can be found online at http://dx.doi.org/10.1016/j.jbiosc.2013.06.013.

We thank Dr. Véronique Alphand and Dr. Alain Archelas for advices in the manipulation of bioreactors and for helpful discussions. We thank Peter J. Punt for the gift of the strain A. niger D15\#26. We also thank Elise Courvoisier-Dezord and the Plateforme AVB: Analyse et Valorisation de la Biodiversité for helpful advices. This work was supported by grants from the Agence National de la Recherche (ANR-08JCJC-0107-01 and ANR-09-BLANC-0176).

\section{References}

1. Kunamneni, A., Camarero, S., García-Burgos, C., Plou, F. J., Ballesteros, A., and Alcalde, M.: Engineering and applications of fungal laccases for organic synthesis, Microb. Cell Fact., 7, 32 (2008).

2. Kiiskinen, L. L., Kruus, K., Bailey, M., Ylösmäki, E., Siika-Aho, M., and Saloheimo, M.: Expression of Melanocarpus albomyces laccase in Trichoderma reesei and characterization of the purified enzyme, Microbiology, 150, 3065-3074(2004).

3. Alves, A. M., Record, E., Lomascolo, A., Scholtmeijer, K., Asther, M., Wessels, J. G., and Wösten, H. A.: Highly efficient production of laccase by the basidiomycete Pycnoporus cinnabarinus, Appl. Environ. Microbiol., 70, 6379-6384 (2004).

4. Rodgers, C. J., Blanford, C. F., Giddens, S. R., Skamnioti, P., Armstrong, F. A., and Gurr, S. J.: Designer laccases: a vogue for high-potential fungal enzymes? Trends Biotechnol., 28, 63-72 (2010).

5. Maté, D., Garcia-Burgos, C., Garcia-Ruiz, E., Ballesteros, A. O., Camarero, S., and Alcade, M.: Laboratory evolution of high-redox potential laccases, Chem. Biol., 17, 1030-1041 (2010).

6. Klonowska, A., Gaudin, C., Asso, M., Fournel, A., Réglier, M., and Tron, T.: LAC3, a new low redox potential laccase from Trametes sp. strain C30 obtained as a recombinant protein in yeast, Enzyme Microb. Technol., 36, 34-41 (2005).

7. Balland, V., Hureau, C., Cusano, A. M., Liu, Y., Tron, T., and Limoges, B.: Oriented immobilization of a fully active monolayer of histidine-tagged recombinant laccase on modified gold electrodes, Chemistry, 14, 7186-7192 (2008).

8. Cusano, A. M., Mekmouche, Y., Meglecz, E., and Tron, T.: Plasticity of laccase generated by homeologous recombination in yeast, FEBS J., 276, 5471-5480 (2009).

9. Punt, P. J. and van den Hondel, C. A.: Transformation of filamentous fungi based on hygromycin B and phleomycin resistance markers, Methods Enzymol., 216, 447-457 (1992).

10. Record, E., Punt, P. J., Chamkha, M., Labat, M., van den Hondel, C. A. M. J. J., and Asther, M.: Expression of the Pycnoporus cinnabarinus laccase gene in Aspergillus niger and characterization of the recombinant enzyme, Eur. J. Biochem., 269, 602-609 (2002).

11. Ahamed, A., Singh, A., and Ward, 0. P.: Chymostatin can combine with pepstatin to eliminate extracellular protease activity in cultures of Aspergillus niger NRRL-3, J. Indust. Microbiol. Biotechnol., 34, 165-169 (2007).

12. Fournier, E.: Colorimetric quantification of carbohydrates, Curr. Protoc. Food Anal. Chem., E1.1.1-E1.1.8 (2001).

13. Yaver, D. S., Overjero, M. D., Xu, F., Nelson, B. A., Brown, K. M., Halkier, T., Bernauer, S., Brown, S. H., and Kauppinen, S.: Molecular characterization of laccase genes from the basidiomycete Coprinus cinereus and heterologous expression of the laccase, Appl. Environ. Microbiol., 65, 4943-4948 (1999).

14. Sigoillot, C., Record, E., Belle, V., Robert, J. L., Levasseur, A., Punt, P. J., van den Hondel, C. A., Fournel, A., Sigoillot, J. C., and Asther, M.: Natural and recombinant fungal laccases for paper pulp bleaching, Appl. Microbiol. Biotechnol., 64, 346-352 (2004).

15. Bradford, M.: A rapid and sensitive method for the quantitation of microgram quantities of protein utilizing the principle of protein-dye binding, Anal. Biochem., 72, 248-254 (1976).

16. Wang, C., Eufemi, M., Turano, C., and Giartosio, A.: Influence of the carbohydrate moiety on the stability of glycoproteins, Biochemistry, 35, 7299-7307 (1996).

17. Vite-Vallejo, O., Palomares, L. A., Dantan-Gonzalez, E., Ayala-Castro, H. G., Martinez-Anaya, C., Valderrama, B., and Folch-Mallol, J.: The role of Nglycosylation on the enzymatic activity of a Pycnoporus sanguineus laccase, Enzyme Microb. Technol., 45, 233-239 (2009).

18. Camarero, S., Pardo, I., Cañas, A. I., Molina, P., Record, E., Martínez, A. T., Martínez, M. J., and Alcalde, M.: Engineering platforms for directed evolution of Laccase from Pycnoporus cinnabarinus, Appl. Environ. Microbiol., 78, 1370-1384 (2012).

19. Simaan, A. J., Mekmouche, Y., Herrero, C., Moreno, P., Aukauloo, A., Delaire, J. A., Réglier, M., and Tron, T.: Photoinduced multielectron transfer to a multicopper oxidase resulting in dioxygen reduction into water, Chemistry, 17, 11743-11746 (2011).

20. Lazarides, T., Sazanovich, I. V., Simaan, A. J., Kafentzi, M. C., Delor, M., Mekmouche, Y., Faure, B., Réglier, M., Weinstein, J. A., Coutsolelos, A. G., and Tron, T.: Visible light-driven $\mathrm{O}_{2}$ reduction by a porphyrin-laccase system, J. Am. Chem. Soc., 135, 3095-3103 (2013). 